\title{
SOCIEDAD, ESTADO, TAL VEZ MERCADO
}

\author{
JORGE HURTADO JORDA
}

Departamento Ciencias Sociales y de la Educación

Universidad de Alicante

\section{RESUMEN}

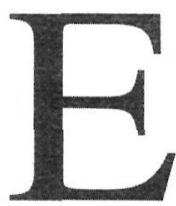

1 artículo versa sobre las relaciones históricamente especificadas entre la sociedad, el Estado y el mercado. Tras exponer el debate teórico sobre estos conceptos, en relación con las corrientes intelectualmente dominantes en los dos últimos siglos, se discute su adecuación analítica y empírica a las realidades del mundo contemporáneo, y particularmente en las últimas décadas. Finalmente se esbozan las ambigüedades y dilemas a los que nos abocan los «usos» políticos, intelectuales y morales de los mismos en relación con los problemas del presente.

\section{CUESTIONES DISPUTADAS}

Conocemos la historia de esos términos, cuya circularidad se ha impuesto con una evidencia más analítica que empírica, como tendremos ocasión de ver. Son una consecuencia intelectual de la ideología liberal que define la «episteme» de las ciencias sociales en el siglo XIX, y que perdura, con crecientes dificultades, hasta nuestros días. De acuerdo con esa ideología, el Estado y el mercado, la política y la economía, son «dominios analíticamente delimitados y en gran medida autónomos, dominios con sus reglas ("lógicas") particulares» (Wallerstein, 1990:402).

Puesto que la realidad desbordaba en fenómenos aparentemente irracionales, que no parecían encajar ni en el dominio del Estado ni en el del mercado, una nueva ciencia debía hacerse cargo de ese conjunto de fenómenos residuales, ajenos a la competencia de la ciencia política y de la economía. La sociología surgirá, así, como la disciplina que se ocupa de fenómenos no lógicos (los «residuos» y las «derivaciones» paretianas, o las «representaciones colectivos» durkheimianas, una especie de sicología de muchedumbres). Por su parte, la antropología se encargaría de esclarecer por qué los pueblos «no civilizados», en el contexto de la 
colonización, son tan imperfectos desde el punto de vista de la naturaleza humana codificada por A. Smith, e impermeables, cuando no resistentes, a la dura carga civilizadora del hombre blanco. Aún, en efecto, no está claro que la mujer y el niño no compartan con el primitivo, en opinión de Levy-Bruhl, una cierta «mentalidad prelógica».

Está por escribir una historia de las ciencias sociales desde esta óptica, una historia que coincidiría bastante estrechamente con el desarrollo paralelo, y sólo aparentemente contradictorio, del universalismo y del sexismo y el racismo (Harris, 1978; Wallerstein, 1988).

Debemos, no obstante, volver sobre los términos propuestos y su adecuación lógica y empírica. Tenemos, pues, la «sociedad» y tenemos el «Estado». La historia del concepto de sociedad es amplia y distinguida. A los efectos de lo que nos ocupa, sin embargo, creo que el concepto de sociedad puede utilizarse como equivalente al de «sociedad civil», en una cierta relación contradictoria pero necesaria con el concepto de «Estado». De hecho, en un principio -digamos desde Aristóteles hasta el siglo XVIII- el término sociedad civil es indistinguible del de comunidad política, cuerpo político e incluso Estado. En la obra de Ferguson - «Essay on the history of civil society»-, la expresión aparece pocas veces, y es aproximadamente sinónima de «sociedad civilizada», de la que el gobierno político es un aspecto esencial. Tampoco Adam Smith incurrió en el descrédito del Estado y de los servicios públicos al que sus tardíos epígonos nos han acostumbrado. Como recientemente han recordado Galbraith o Chomsky (Galbraith, 1992; Chomsky, 1993), Smith no sólo consideraba necesaria y útil la existencia de un Estado prestatario de servicios, sino que era partidario de un impuesto proporcional sobre la renta, y juzgaba tan contraproducente para la creación de riqueza el excesivo intervencionismo público como los privilegios monopolistas de las grandes empresas, siempre prestas a conjurarse contra el consumidor.

Es, por tanto, en el siglo XIX cuando «la gente - la gente liberalcomenzó a distinguir entre sociedad y Estado» (Dahrendorf, 1990:58). La razón de esta distinción es la contraposición, típica de la historiografía dominante, entre una sociedad articulada ya por los intercambios mercantiles y las relaciones económicas capitalistas, y un Estado que era aún expresión del viejo régimen. «Citoyen»y «bourgeois» parecen ser, así, dos caras de la misma moneda, aunque en realidad no lo sean — dice Dahrendorf-, y el concepto de ciudadanía perdure como real o deseable una vez que la burguesía haya abandonado el centro de la escena social y política.

El hito (o el mito) político que, se supone, sutura la distancia entre economía y política será la Revolución Francesa y las transformaciones ideológicas que induce, transformaciones que configurarán una auténtica divisoria histórica y que, a los efectos de nuestro interés, pueden reducirse a dos (Wallerstein, 1990). 
Por una parte, lo normal es el cambio, frente a la experiencia de las sociedades preindustriales, ancladas en una estasis social periódicamente sacudida por revueltas que concluyen en la restauración del mismo sistema, aún si han conseguido modificar parcialmente la composición de las élites políticas o burocráticas.

Por otra parte, la reconciliación - siempre conflictiva, recurrentemente problematizada - entre política y economía, Estado y mercado, abrirá paso a una antítesis más laxa pero más vasta: en adelante, la sociedad se opondrá al Estado, no sólo en tanto que las leyes que gobiernan su funcionamiento respectivo son diversas, sino en cuanto a la discusión sobre a quién corresponde la prioridad del cambio y cómo corregir las asimetrías entre sus respectivos desarrollos.

\subsection{La prioridad del cambio}

Como es sabido, las ideologías contemporáneas - conservadurismo, liberalismo, socialismo- se diferencian entre sí, precisamente, por su actitud ante el cambio. Para los reaccionarios, las grandes conmociones sociales no sólo son más aparentes que reales, un pliegue en el orden invariable del mundo, sino que, además, generan efectos «perversos» - contrarios a los ingenuamente perseguidos-, y multiplican el riesgo siempre acechante del desorden (Hirschman, 1991). En consecuencia, aún el cambio ilusorio debe ser contrarrestado, circunscrito, ralentizado en una suerte de viaje inmóvil.

El liberalismo, por el contrario, exhibió desde sus orígenes, para horror del conservadurismo, un pathos fáustico, un impulso impersonal pero necesario en favor de la disolución de todo orden estable, de toda ligadura, de toda lealtad personal o social (Berman, 1988). Ahora bien, inhábil para controlar o encauzar los impactos del sistema económico, regido por la acumulación incesante, ha pretendido que el orden cultural y moral tomara el relevo en la definición, siempre ambigua, de la norma y la desviación, restringiendo la libertad sin medida al ámbito exclusivo de lo tecnoeconómico (Parsons, 1968; Bell, 1977).

En cuanto al socialismo, su posición frente al cambio es paradójica. Frente al conservadurismo, reivindica el cambio y la renovación de las viejas y anquilosadas estructuras, la «tradición de las generaciones muertas oprimiendo como una pesadilla el cerebro de los vivos» (Marx). Así, Spencer y Marx coincidirán en la necesidad de superar las constricciones sociales petrificadas en el Estado, y en liberar al individuo de toda traba (Gouldner, 1983:104). Frente al liberalismo, sin embargo, la emancipación de los individuos concretos exige el control de las fuerzas económicas y su subordinación a la libre expresión de la riqueza humana y sus potencias. La libertad y plasticidad moral primarán sobre la libertad económica. 
Naturalmente esta apretada e insuficiente síntesis es sólo teoría, «retórica» si queremos hollar el campo abierto por Hirschman. En los hechos, el conservadurismo propició cambios de hondo calado y trascendencia (los derechos políticos británicos, o los derechos sociales bismarckianos). El liberalismo incorpora una fuerte orientación antiindividualista, una constante restricción de la competencia y una estrecha dependencia del Estado (Balibar y Wallerstein 1991:226). El socialismo, en fin, no sólo ha reforzado el Estado en vez de disolverlo, sino que ha mostrado incluso mayor hostilidad a la diferenciación y a la libertad moral de los individuos que a su misma libertad económica.

Ahora bien, al menos hasta tiempos bien recientes, si en algo hay coincidencia entre las tres corrientes, más allá de sus declaraciones programáticas, es en el papel central otorgado al Estado como agente regulador del cambio y como promotor de una cierta división interestatal del trabajo.

Difícilmente podría ser de otro modo. El siglo XIX se caracteriza por la intensidad y extensión de las guerras internacionales, las disputas políticas internas y la exacerbación de la lucha de clases - la Revolución de 1848 , la Comuna de 1871- , y por una desatada competencia económica interimperialista. Los modernos estados europeos eran, en realidad, auténticos mosaicos físicos, lingüísticos, culturales, religiosos, a los que se superponían, a menudo violentamente, las instituciones formales, las normas constitucionales, las instancias de control social.

El Estado poseía, así, una compacidad directamente observable, que contrastaba con la radical heterogeneidad del mundo social, por igual excluido de la economía y la política, del mercado y del Estado, de la ideología de la «nueva clase» y de su reivindicación de un gobierno mínimo para el capital, máximo para los desgraciados e investido de «razón» en las relaciones interestatales.

\subsection{La sociedad}

El problema de la sociedad, la sociedad como problema, independiente del Estado y, para muchos, del mercado, de cuyos efectos disolventes pretende defenderse en el período (Polanyi, 1989), surge al mediar el siglo XIX. Ciertamente, en su primer tercio resuenan las catastróficas profecías incumplidas de Burke, De Maistre y Bonald, sobre las consecuencias de la Revolución. Entrado el siglo, sin embargo, empieza a aceptarse no sólo que el cambio rige la modernidad, sino que éste puede ser controlado.

El problema estriba en comprender el funcionamiento de ese tejido más desestructurado, menos tupido, pero más perdurable y resis- 
tente, que llamamos sociedad -es decir, lo que no es ni Estado ni mercado-, y procurar su reconciliación, su acuerdo en la dirección y los ritmos, con las tendencias subyacentes del movimiento económico y su regulación política.

La moderna ciencia social surgirá entonces con la promesa explícita de realizar este programa: explicar el movimiento interno de la historia, procurar una idea de comunidad deseable, y poner a punto las técnicas sociopolíticas que crearán esa comunidad y resolverán los desajustes manifiestos, las divergentes durées de las mutaciones económicas, los avatares de la política y la gruesa urdimbre de los usos y costumbres, incluyendo la «vida material», para emplear la distinción de Braudel (Braudel, 1968, 1985). Es decir, como resumió el padre de los «padres fundadores» de la sociología, en memorable expresión: "savoir pour prévoir et prévoir pour pouvoir» (Comte, 1967).

Desde luego, para ello es necesario aceptar que la configuración de la sociedad no es algo aleatorio que los hombres puedan hacer y deshacer a su antojo, como pensaban los revolucionarios. Las sociedades tienen, al igual que los fenómenos naturales, sus propias leyes de desarrollo y funcionamiento, y sólo conociéndolas se puede actuar sobre ellas, garantizando una sabia combinación de «orden y progreso».

No es necesario señalar, como vitriólicamente ha hecho N. Birnbaum (Birnbaum, 1982:110-111), en qué medida la magnitud del programa de la sociología explica mejor que todo sus intentos de refundación la paralela magnitud de su fracaso. No obstante, como ha hecho notar Wallerstein, desde entonces «se ha librado un enorme debate acerca de cómo se relacionan la sociedad y el Estado, cuál estaba o debería estar subordinado al otro, y cuál encarnaba los valores morales más elevados» (Wallerstein, 1990:407).

Lo sorprendente es la escasa claridad que se desprende de tan enconado debate. Y es que para unos la sociedad sigue siendo ese flujo de intercambios contractuales de sujetos racionales, previos a las regulaciones estatales, que inauguran inexorablemente el «camino de la servidumbre», y la libertad consiste, fundamentalmente, en la capacidad de elección del... consumidor (Friedman, 1983). Otros, por el contrario, mantienen un concepto de sociedad relativamente libre de adherencias estatales y distinto del mercado, próximo a la lenta pero incesante reivindicación de «titularidades», bien sean necesidades básicas, derechos políticos o derechos sociales, es decir, el problema de la «ciudadanía» (Marshall, 1963; Dahrendorf, 1990). Por último, sin que ello signifique exhaustividad, para muchos la noción de sociedad es casi fronteriza con la de «comunidad», y remite a circunstancias y hechos en cierto modo presociales, universales, cambiantes pero eternos, tales como las pautas demográficas, la familia y 
la distribución de roles en su interior, los cambios lentos en la vida privada, las creencias y valores, que pivotan sobre unas pocas antinomias, etc.

Por ejemplo, en un texto reciente puede leerse este inteligente (e inteligible) alegato:

«Se va a hablar aquí de sociedad, y no tanto de España, porque en los usos lingüísticos actuales, cuando se habla de "España" los textos suelen centrarse en lo que el gobierno ha hecho por la prosperidad del país. En realidad, referirse a España está significando la conducta de unos pocos españoles, los políticos. Esta transmutación no es inocente. Supone que lo que acontece a la sociedad es consecuencia directa y racional de lo que ha planeado el Gobierno, lo que ha intentado mediante cambios legislativos o de personal político. Estas páginas rechazan ese reduccionismo. La sociedad evoluciona o se mantiene con cierta prescindencia de lo que proponen los gobiernos. El desarrollo económico, el cambio social y político es bastante más que las consecuencias de éstas o las otras políticas. Esa autonomía de la sociedad respecto del gobierno o incluso del Estado es ya un rasgo de modernidad que puede predicarse de los españoles» (De Miguel, 1992:18).

La cita es larga, pero permite deducir varias conclusiones esenciales. En primer lugar, la sociedad no es el gobierno ni siquiera el Estado. En segundo lugar, la sociedad evoluciona y se mantiene independientemente del Estado. En tercer lugar, esa autonomía de lo social es un rasgo específicamente moderno que puede predicarse ya de los españoles.

La primera conclusión remite a esa lenta emergencia y diferenciación de lo social del seno del Estado, al que ya hemos aludido. La segunda da cuenta de esa atribulada asimetría entre la sociedad y el Estado. La tercera, en fin, sugiere que el cambio es constante, pero que también es cierta la afirmación contraria: nada cambia jamás, simplemente varía, se transmuta, oculta la igualdad bajo la diferencia.

Sin embargo, lo indubitado es «España» y «los españoles». Existe un Estado llamado España, al que subyace una sociedad, la española, que envejece y enferma, retrasa la edad del matrimonio y cohabita; que se ocupa del cuerpo, se hace individualista, tiene problemas, se educa y trabaja (mucho los que trabajan, pocos; menos los que no trabajan, demasiados). La sociedad española, sin embargo, ¿la componen españoles?

No está claro, se nos informa sorprendentemente en el citado Informe (Jiménez Losantos, en De Miguel, 1992:684 y ss.). En realidad, sólo algo más de una quinta parte de los españoles consultados en los últimos años a través de encuestas escoge el gentilicio «español» como su gentilicio favorito. El resto se identifica preferentemente con «su pueblo» $y$, en menor medida, con su provincia, su co- 
munidad, Europa, Occidente, el mundo, o con ningún gentilicio, en orden relativamente variable. Como señala el autor, sin embargo, no se trata de que los españoles renieguen de serlo o quieran ser otra nación (vascos, catalanes, andaluces, etc.), lo que sucede en pocas ocasiones, sino que se identifican con territorios simbólicos no coincidentes con el Estado llamado España.

No vale la pena que los antropólogos — salvo que sean norteamericanos, es decir de muchas partes y de ninguna parte- se maravillen de esta peculiaridad pretendidamente premoderna de los españoles. Tendrían que volver a mostrar idénticos signos de estupefacción en casi todas las naciones europeas, fragmentadas por motivos lingüísticos, religiosos, culturales, sociales, políticos o económicos. Como en un palimpsesto, en este fin de siglo lo viejo reaparece bajo capa de modernidad, la globalización se traduce en reivindicación de singularidades, y la unificación del mercado cuestiona el estado y reabre con fuerza inusitada las viejas líneas de segregación, incluso en el lenguaje social y político, llámense razas, etnias, grupos de status, sexos o edades.

Y si esto sucede en los viejos Estados centrales, ¿qué decir de los surgidos del tiralíneas colonial o de la decretada abolición de las diferencias en el totalitarismo comunista? Como ejemplo, baste con señalar que existen en el mundo muchos menos Estados monolingües (6) que con más de cincuenta lenguas en su interior (28), y que los Estados con más de tres lenguas representan más del $80 \%$ de los existentes (Tortosa, 1992:140).

\subsection{La(s) ciencia(s) social(es)}

¿Debemos concluir, por tanto, que la sociedad no existe, o que su concepto es demasiado confuso? No son pocos los sociólogos que abogan, paradójicamente, por la abolición del concepto de sociedad (Mann, 1991:15). Lo que está en crisis, sin embargo, no es sólo la sociedad - ni la sociología como la ciencia que se ocupa de la misma-, sino su percepción como un vector incontaminado por la economía y/o la política, el mercado o el estado, organizados, además, sobre una base nacional, que permite diferenciar con claridad los factores «internos» de los «externos», los exclusivos del Estado-nación y los derivados del sistema interestatal de la economía-mundo. Con mayor evidencia aún, está también en crisis la distinción entre un «ecosistema» externo, puro soporte irretroactivo, y los subsistemas analíticos que llamamos población, economía, política o cultura ( $\mathrm{Ji}$ ménez Herrero, 1989).

Tampoco se trata del conocido problema de la «interdisciplinariedad», que parte del supuesto de que la complejidad de los sucesos 
aconseja un abordaje múltiple desde las distintas tradiciones académicas con el fin de iluminar aspectos varios de problemas con dimensiones poliédricas, y cuya virtualidad consiste en fijar las barreras respectivas de las diversas disciplinas (Wallerstein, 1990).

Se trata más simplemente de reconcer, como sugeríamos al principio, que no existen «leyes» del movimiento económico, ajenas a la política, la sociedad y la cultura, del mismo modo y en el mismo sentido que no puede comprenderse la evolución del Estado sin ponerla en relación con la ecología o la evolución de la cultura, y no en tanto que transformación de una forma pura, de una cierta «idea» que transmigra, imperfecta, hasta la reconciliación final consigo misma.

No es tampoco que tales distinciones carezcan en absoluto de sentido, o que no hayan dado cuenta de situaciones identificables empíricamente durante largo tiempo. Pero hay señales abrumadoras, y una creciente e implacable evidencia epistemológica, de que las viejas barreras entre ciencias duras y blandas, y en el interior mismo de las ciencias sociales, se derrumban, y que vastas colecciones de sucesos requieren para su explicación de una scienza nuova, que no tendrá el nombre de las viejas disciplinas (Oltra, 1984, 1993; Capra, 1985).

Esas recientes mixturas que aparecen en los márgenes de la «ciencia normal», infectándola e infiltrándola, y que cruzan las fronteras establecidas - - ecología económica, sociología histórica o historia sociológica, teoría de sistemas, etc.- preludian su ruptura.

\section{UN ESTADO DE INCERTIDUMBRE}

El capitalismo histórico no esperó, pese a todo, a conocer las leyes internas de la sociedad para resolver el desafío que representaban esas masas liberadas de la comunidad tradicional y crecientemente dependientes de rentas salariales, aunque, desde luego, el salario siguiera siendo sólo una, y no la más importante, de las posibles fuentes de renta para su supervivencia (Pahl, 1991).

Sin embargo, en tanto que otra(s) nación(es) dentro del Estado representaban un riesgo insoslayable, en el mismo momento en que la ideología triunfante del individualismo competitivo eximía a las clases dominantes de toda obligación moral o redistributiva con respecto a las clases subordinadas.

\subsection{El Estado liberal}

Se olvida, así, hasta qué punto el movimiento histórico real desdijo a Spencer, y en qué medida el Estado liberal incumplió sus autoprescritas obligaciones. Por motivos poco extraños, se ha impuesto la 
idea de que el capitalismo, en su dorada fase decimonónica, implicaba la actividad de empresarios privados liberados de las interferencias de los aparatos estatales, y que el creciente peso del Estado en la actividad económica - y en su regulación- ha supuesto una constante redistribución de capacidad económica en favor de los desfavorecidos, un cierto impulso a la nivelación social.

A tal punto está arraigada esta idea que, en verdad, es fácil desfallecer si se quiere sostener la carga de la prueba contraria. Por supuesto, no se trata sólo de demostrar que en el estricto sentido en que Braudel se refiere al «capitalismo» como algo diferente de la «vida material» y del «mercado», «...estos capitalistas, tanto en el Islam como en la Cristiandad, son los amigos del príncipe, aliados o explotadores del Estado» (Braudel, 1985:69). Se trata, además, de señalar que el mecanismo entero de la acumulación de capital es imposible sin el activo concurso de un Estado, cuya construcción es uno de los logros institucionales del capitalismo, y una palanca esencial en el proceso de polarización de los ingresos.

Desde luego, en el sistema interestatal de la economía-mundo, respaldando y reforzando las «ventajas comparativas», modificando fronteras, abriendo mercados, asegurando el abastecimiento de materias primas y energía barata, o disuadiendo mediante el poder militar a los competidores económicos. Pero también en el interior de los Estado-nación centrales, a través de la legislación laboral, de la regulación de las relaciones sociales, y del reforzamiento de la capacidad impositiva, mucho menos redistributiva, en el sentido progresivo actual, de lo que parece (Wallerstein, 1988:36-65).

Por una parte, el Estado apoya la acumulación de capital, a través de la subvención directa (bonificaciones, exenciones, incentivos a la inversión, ayudas a la exportación, precios garantizados, etc., en el lenguaje de la contemporánea crematística). En segundo lugar, hoy como ayer, en el capitalismo tardío como en el primer capitalismo, la usurpación de fondos públicos y la malversación a gran escala, a través de diferentes medios, ha sido una constante, trátese de los explotadores del Estado del capitalismo originario o de las generalizadas prácticas corruptas que, por doquier, salpican las páginas de prensa. Este «sistema oculto» (Tortosa, 1992a:40) no sólo no es marginal, una simple excrecencia patológica, sino que activa el sistema en su conjunto, al punto de motivar incómodas preguntas. Por ejemplo, en los años ochenta de este siglo, esos dos «milagros económicos» que son Japón e Italia, ¿lo fueron potencialmente más o menos en función de su generalizada corrupción? ¿Fue la «libre competencia» o la «competencia oculta» por las rentas públicas lo que propició el éxito de los modernos condottieri? Por último, la socialización del riesgo y la individualización de la ganancia es una práctica tan habitual, e inherente al funcionamiento del mercado - no sólo un mecanismo efi- 
ciente para la asignación de recursos económicos, sino un conjunto complejo de reglas y restricciones, permanentemente reelaboradas y ajustadas-, que tendemos a considerarla más un «servicio público» que un apoyo público al capital privado, trátese de I+D, infraestructura informacional, redes de transporte y energía, o desarrollo de nuevos productos, como si sus efectos se deslocalizasen equilibradamente por todo el cuerpo social.

En cuanto a los Estados del Tercer Mundo o del antiguo Segundo Mundo es, por supuesto, difícil magnificar la medida en que son mecanismos al servicio de la exacción de la mayoría en beneficio de la minoría, estrangulando incluso las iniciativas marginales de acumulación de capital, el vasto terreno de la «informalidad» (De Soto, 1986; Sanchís y Miñana, 1988).

¿Por qué, entonces, esa extendida presunción sobre el papel nivelador del Estado, sobre su carácter redistributivo en favor de los débiles? He aludido ya a la extrema fragmentación de las sociedades en el siglo XIX, bullentes calderas en las que, quebrados los cuadros sociales y las comunidades tradicionales, proliferan las «clases peligrosas»: criminales, mendigos, locos y proletarios. Es en este marco también en el que se aprueban las Leyes de Pobres, precedidas y seguidas de una nutrida crítica sobre la «ingenuidad» de la medida y su inherente efecto de incitación a la pereza, la depravación y el vicio. Ahora bien, como señalara Marshall (Marshall, 1963), la Ley de Pobres aprobada en Inglaterra en 1834 -con precedentes en 1601 y en la Ley de Speenhamland de 1795, dictados en condiciones, para fines, y con agentes diferentes - implicaba para el tutelado la renuncia a todo derecho civil y político y a la propia libertad personal. $\mathrm{O}$, en otros términos, los derechos sociales, en la terminología de Marshall, aún se contraponían a los derechos fundamentales, que tutelaban la libertad personal, política y económica. Esos derechos fundamentales eran, por otra parte, la garantía de una sociedad (burguesa) supuestamente separada del Estado, mientras que los derechos sociales representaban la vía a través de la que la sociedad en su conjunto entra en el Estado alterando su estructura formal.

\subsection{Orígenes del Estado social}

Será en la segunda mitad del siglo XIX y, sobre todo, en su último tercio, cuando - con las restricciones clasistas, sexuales, etarias y étnicas conocidas, que perdurarán prácticamente hasta la segunda mitad del siglo XX-- se inicia la gradual integración del Estado político y de la sociedad civil, es decir, en el sentido restrictivamente negativo acotado antes, lo que no es Estado. Dicha integración pasará por la paulatina extensión del sufragio, que a fines del siglo hace conce- 
bir al viejo Engels la esperanza de un acceso al poder vía electoral; por una mejora de las condiciones de vida de las clases populares, hecha posible por los incrementos de productividad; $y$ por el colonialismo, que cobra renovado rigor en los años ochenta del pasado siglo, y que concluye con el reparto imperial de Africa y Asia entre las potencias europeas, y el protectorado estadounidense sobre América Latina.

Democracia y desarrollo económico son, pues, las claves de la progresiva integración de las «clases peligrosas» en el sistema, integración que se verá reforzada a través de nuevos vínculos culturales e ideológicos. El primero de ellos es la consolidación de un cierto nacionalismo económico como ideología del desarrollo, cuyo agente fundamental será el Estado, bien para paliar los costes de las «catástrofes culturales» que inflige el mercado, en el caso de los conservadores; bien como regulador del cambio, según el reformismo paulatino y racional de los liberales; bien como la palanca esencial para la transformación social en el caso de socialismo, sobre todo en su triunfante versión lassalleana. El patriotismo suturaba, así, las divisiones internas, dotaba a los pueblos de un hipotético pasado común y del señuelo de un destino, y predisponía a la competencia y a la guerra.

El segundo vínculo es la etnificación de la fuerza de trabajo y el racismo imperialista, ya no una distinción moral y política entre los miembros de un grupo y los «otros» despreciados y/o temidos, sino una estructura institucional que da cuenta de la división del trabajo en la economía-mundo y que se traduce en estructuras productivas y costes salariales espacialmente diferenciados (Wallerstein, 1988).

Esta lógica sugiere varias inversiones importantes en el conocimiento comúnmente admitido sobre el mundo moderno. En primer lugar, los Estados-nación son una creación de la economía-mundo capitalista. Pocos de entre los actuales estados, incluso en los países desarrollados, pueden «reivindicar un nombre y una entidad administrativa permanente en la misma ubicación geográfica antes de 1450 » (Balibar y Wallerstein, 1991:126), e incluso estos pocos surgen como estados soberanos con el sistema mundo-capitalista. En segundo lugar, frente a las mitologías nacionalistas y el arraigado binarismo entre la sociedad y el Estado, «un examen sistemático de la historia del mundo moderno mostrará que en casi todos los casos el Estado ha precedido a la nación y no a la inversa» (Balibar y Wallerstein, 1991:127).

Es decir, no existe una «nación», un «pueblo» o una «sociedad», con sus rasgos distintivos, sus diferencias genéticas, su historia y tradiciones, su cultura, buscando esculpir su identidad en un estado propio, sino que en muchos sentidos, y con éxito diverso, el estado «inventa» un pueblo y desarrollo un sentimiento de pertenencia inestable basado en la ilusión de un origen y un destino común. Que 
el destino no suela ser manifiesto y que el pasado no sea inmutable, que siempre quepa la referencia a otro pasado más lejano o «diferente», da la medida de esa inestabilidad, y nos instruye sobre el modo en que el tiempo anterior no es un depósito fijo, sino una función moral y política de los problemas y aspiraciones del presente.

El nacionalismo estatal -puesto que existen también nacionalismos subestatales y supraestatales, cada uno con sus temporalidades y mitologías diferentes- cumple, de este modo, varios propósitos significativos. En primer lugar, permite la utilización de los poderes legales del Estado en beneficio de unos grupos frente a otros grupos excluidos y/o con base no estatal. En segundo lugar, refuerza la cohesión social, frente a las amenazas externas y los peligros de desagregación interna. En tercer lugar, favorece la «gubernamentalidad» y la eficacia y simplicidad administrativa, mediante el desarrollo de la «estadística» - ciencia del Estado - y de la economía, como algo diferente del gobierno de la familia, su definición originaria (Foucault, 1981).

Más profundamente, en fin, el nacionalismo estatal pone de relieve que el sistema interestatal de la economía-mundo no es una yuxtaposición de Estados soberanos, sino un sistema profundamente jerarquizado, aunque móvil, en el que una nación sin Estado, o un Estado sin nación, no tendrían la posibilidad de alterar su posición en el sistema, no serían jugadores en ese juego variable y, paradójicamente, estable, al contrario que en sistemas sociales anteriores en el que las entidades políticas y las naciones no necesitaban ser coincidentes.

\subsection{El Estado del bienestar}

La historia del Estado del bienestar es suficientemente conocida (García Cotarelo, 1986, 1987; Ritter, 1991). Dimana de esa necesidad de integración de las «clases peligrosas», y se apoya en los mecanismos que la hicieron posible: desarrollo económico, democracia política, patriotismo imperialista y racista. Su antecedente remoto son las ya citadas Leyes de Pobres, que constituían un compromiso entre la vieja caridad y la necesidad de subvenir la reproducción de la fuerza de trabajo por encima del mero nivel de subsistencia. También las legislaciones fabriles, que limitaron el trabajo de mujeres y niños, pueden considerarse precedentes en el mismo sentido.

Sin embargo, los primeros elementos activos del Estado del bienestar aparecen, a partir de 1848, en Estados autoritario-paternalistas, no sujetos a formas de legitimación legal-racional, tales como la Francia de Napoleón III o la Alemania bismarckiana. Incluso en España, la Comisión de Reforma Social, fundada en 1883, fomenta una política social que intenta paliar los estragos del liberalismo. 
En cuanto a sus orígenes intelectuales, los Talleres Nacionales de Louis Blanch, el socialismo de cátedra alemán (la «Verein für Sozialpolitik»), el socialismo estatista y reformista de Lassalle, el cartismo inglés y el socialismo fabiano, y la misma doctrina social de la Iglesia, coadyuvan a poner las bases de un Estado del bienestar, sensible a la cuestión social y a la incesante reivindicación de igualdad y dignidad de los individuos.

Pero es, sin duda, en el siglo Xx que los derechos sociales y las políticas sociales desarrollan y amplían los derechos civiles y políticos, y que el Estado de Bienestar conoce un desarrollo masivo. En principio, es una reacción a la crisis de 1929 —en realidad, al largo período de declive que se inicia en la Primera Guerra Mundial y que concluye tras la Segunda Gran Guerra-, y un intento de regular las recurrentes crisis cíclicas del capitalismo y sus amenazantes secuelas. El New Deal roosveltiano (1932-1936) y los Acuerdos de Saltsjöbaden (1938) en Suecia constituyen los antecedentes más notorios de una política que intentaba conjugar las necesidades de la acumulación de capital y los problemas de legitimación política, a través de la constitución de un mercado de trabajo permanente y estable, de la regulación de la demanda, y de la parcial integración del conflicto social y de las reivindicaciones de un movimiento obrero, que alentaba aún en su interior fuertes corrientes radicales y antisistémicas.

Dichas políticas, como es sabido, encontraron su formulación teórica y su síntesis práctica en la Teoría General de Keynes (1936), que alumbrará dos vástagos muy diferentes. Por una parte, el keynesianismo militar de los fascismos europeos y del expansionismo japonés. Por otra, tras la devastación de la Segunda Guerra Mundial, un tipo de Estado, sobre la base de un pacto social entre patronal, gobierno y sindicatos, que combinará democracia y planificación, libertad económica y control de la demanda, elección individual y redistribución, libertad personal y justicia política.

Dicho pacto se apoyaba, además, en un consenso en el que participaban las corrientes políticas dominantes - liberalismo, socialismo, democracia cristiana e, incluso, comunismo-, y que epitomiza el Informe Beveridge (1942) y sus expansivos efectos hasta la nueva crisis económica, que se inicia en el período 1968-1973.

No debería creerse, sin embargo, que el keynesianismo y el Estado del bienestar se impusieron con la fuerza de lo ineluctable. Fueron, sin duda, una consecuencia del «gran miedo» tras una crisis prolongada, cuyos efectos se plasmaron en dos Guerras Mundiales, decenas de millones de muertos, los fascismos y el stalinismo, por citar sólo algunos episodios relevantes en la arena europea. Pero nada conmovió la fe en el largo plazo del mercado de los partidarios del laissez-faire. El New Deal fue criticado y ridiculizado como una ex- 
centricidad insoportable por una teoría económica acomodada en exclusiva a los severos intereses de la «ciencia», y el Tribunal Supremo de los Estados Unidos intentó excluir de las filas constitucionales la amenaza del intervencionismo keynesiano (Galbraith, 1992; García Cotarelo, 1987). Aunque la respuesta de Keynes fue contundente «a largo plazo todos muertos»- no es nada probable que se aprendiera la lección.

La viva claridad de los veranos es corta. Durante poco más de dos décadas —años 50 y 60 - las políticas sociales y el Estado del bienestar se concibieron como parte de un proceso evolutivo en favor de la igualdad (Marshall, 1963), como compensación a los costes del crecimiento y de los procesos de industrialización (Galbraith, 1967), o como un modo de integración de los trabajadores y de gestión de la fuerza del trabajo en la nueva dinámica del «fordismo». Si se quiere, en fin, como un vínculo de unión, de articulación contradictoria, entre los sistemas de capitalismo avanzado y la democracia política de masas (Rodríguez Cabrero, 1982).

Ese equilibrio era inestable. Se sostenía, desde luego, en la clara hegemonía de los Estados Unidos - frente a las rivalidades interimperialistas del período anterior-, y en un intercambio desigual con la periferia, que permitía la transferencia de plusvalía desde el Sur hasta el Norte industrializado, y su redistribución en los países centrales. Al mismo tiempo, el keynesianismo y las políticas de bienestar incrementaron la fuerza estructural del trabajo en los países avanzados, favoreciendo la «revolución de las expectativas»y sustituyendo la racionalidad económica por la irracionalidad de las demandas políticas.

Así, con la crisis del petróleo y el incremento del precio de los alimentos y de las materias primas, llegan las frías tinieblas. No vale la pena repetir los términos de una polémica, que entre nosotros ha sido múltiplemente examinada y periodizada por Rodríguez Cabrero (Rodríguez Cabrero, 1982, 1992). Básicamente, lo que se discute, para nuestros propósitos, es si el Estado del bienestar y sus políticas aherrojan a la sociedad, disuaden el espíritu de logro, someten a la democracia a tensiones ingobernables, y atentan contra los equilibrios económicos básicos. O si, por el contrario, la capacidad de integración del sistema se ha agotado, si su crisis es global y, en consecuencia, si el tránsito del Welfare al Workfare no establece los límites de una nueva fragmentación social que parecía conjurada.

\section{TAL VEZ MERCADO}

Permítaseme ahora aclarar esa leve vacilación shakespeariana que sugiere el título del artículo. Hemos hecho referencia a la sociedad y 
al Estado, relativizado su definición y problematizado su relación. Sociedad, en efecto, parece ser un concepto arrojadizo y móvil. Para algunos, simplemente, lo que no es Estado, lo que desborda la sociedad política, burocráticamente organizada en jerarquías de poder piramidal. Esta definición mínima, sin embargo, no está exenta de problemas. Los unos apelarán, entonces, a una sociedad civil entendida como el mundo privado de lo económico, el reino del mercado, en el que individuos libres y racionales -maximizadores del propio interés, conforme al concepto de «racionalidad» económica- interactúan ordenando sus preferencias en una función de utilidad. Otros, por el contrario, denominarán sociedad a lo que no es estado ni mercado, ni sociedad política ni sociedad civil, ni poder ni capital.

En cuanto a los problemas de la «ciudadanía», los partidarios de la sociedad civil prefieren hacer hincapié en la «ciudadanía activa» a fin de desarrollar los deberes de los ciudadanos (Dahrendorf, 1993), mientras que los que no asimilan sociedad y mercado preferirían también eludir las trampas del Estado - la burocratización, el sexismo, la definición profesional de las necesidades, etc.--, para plantear una política propiamente social. Es decir, desearían definir una «ciudadanía comunitaria» y sobrepasar el Estado de bienestar en favor de una «sociedad del bienestar» (Rodríguez Cabrero, 1992; Sotelo, 1993).

El problema de esa apelación a una «sociedad impropia», ajena al Estado y al mercado, es que, pese a su preeminencia estadística, no es fácilmente discernible cuando al tiempo se advierte que la dinámica de la acumulación ha disuelto en la mercantilización generalizada el «mundo de la vida», la densidad asociativa de los grupos primarios, las raíces comunitarias y el acervo de tradiciones preburguesas (Habermas, 1973). En varios sentidos, como hemos visto, la sociedad -civil o impropia - no ha sido extraña al Estado acerbo, al ogro filantrópico, al insaciable Leviatán, con sus férreas redes corporativas. Otra cuestión, bien diferente, es que hayan cambiado las funciones de ese Estado.

Hemos visto, en efecto, cómo el Estado del bienestar tuvo entre los años 50 y 68/73 la función de integrar el conflicto, legitimar en los países centrales la dinámica de la acumulación y regular el ciclo económico. Se trataba, en definitiva, de proteger el cuerpo social de las catástrofes del mercado. Desde finales de los sesenta, sin embargo, y a impulsos de la globalización, las prioridades cambian. El Estado pasa a ser una especie de agente promotor del desarrollo, vinculado al capital privado, cuya función es adaptar la economía nacional a las nuevas reglas de la economía mundial. El Estado se convierte, como señala Tortosa sucintamente, en «correa de transmisión de la economía mundial a la economía interna» (Tortosa, 1992a:23).

El cambio en las modalidades de intervención del Estado pasa, como es sabido, por un paulatino abandono de las funciones de legitimación en favor de las funciones de apoyo a la acumulación, con- 
forme a modelos de desarrollo diferenciables, pero que comportan una activa transferencia de fondos estatales a la actividad económica privada (Castells, 1987). De hecho, la competitividad en la nueva economía globalizada parece depender estrechamente, como se deduce de la experiencia japonesa y del modelo de desarrollo de los nuevos países industriales asiáticos, de la capacidad política de las instituciones estatales - y subestatales o supraestatales - para programar y dirigir el desarrollo económico, conforme a iniciativas estratégicas sin paralela ideología estatista (Jhonson, 1982; Bustelo, 1990).

No hay, por tanto, rolling back del Estado, sino un cambio de acento, una transformación de sus formas de intervención, acompañada de una redistribución regresiva, cuyo único límite hasta el presente han sido las prestaciones sociales universales y la elevada factura de un desempleo creciente. Las transformaciones en la estructura de clases - en el sentido de un mayor peso de los autónomos, microempresarios y trabajadores independientes en detrimento de la clase obrera tradicional y los asalariados-, y los concomitantes cambios culturales e ideológicos abonan, sin embargo, el terreno para un recorte paulatino y legitimable del «núcleo duro» de un Estado del bienestar, cuyas deficiencias y distorsiones - burocratismo, despilfarro, falta de selectividad, rigidez, sexismo, agencia de heteronomía, horizontalidad, etc. - son duramente resaltados en favor de su erosión (Muñoz de Bustillo, 1989).

\subsection{Por un mercado menor}

Se supone, en principio, que con el desmantelamiento selectivo del Estado del Bienestar, el mercado y la sociedad civil cobrarían un vigor renovado. Se supone también que, con la suspensión o la administración condicionada de subsidio y ayudas del gobierno, se quebraría la natural predisposición a la indolencia de los desfavorecidos, alimentada por una cultura de crecientes demandas desligadas de sus costes, y que renacería una apremiante competencia en favor del trabajo y del esfuerzo.

No está claro, sin embargo, ni que el mercado se amplíe ni que la sociedad civil se vigorice. Apurando la paradoja, la futilidad del esfuerzo es, posiblemente, la única lección deducible por una legión de excedentes, cuyo peso creciente les ha hecho acreedores de un neologismo - «infraclases»-, que recuerda otras fórmulas antiguas - el «lumpemproletariado»-, cuando aún existía el proletariado como el más bajo umbral clasista, y aún las sociedades avanzadas no eran sociedades de clases medias con límites borrosos y calidoscópicos.

Desde luego, la «sociedad civil» no prospera. En tiempos menos reduccionistas, por «sociedad civil» se entendía un conjunto de or- 
ganizaciones autónomas, de grupos, de movimientos, que vinculaban a los ciudadanos entre sí y con las instituciones políticas. Ahora bien, el declive de esas asociaciones en favor del privatismo civil y el paralelo ascenso del individualismo es un lugar común de la sociología y la filosofía del período, pese al renacer de las «tribus». Y los sindicatos, el más claro ejemplo de densidad asociativa, atraviesan una crisis aguda, patente en su bajo nivel de afiliación y en su creciente irrelevancia en las actividades de servicios y en las pequeñas empresas tecnologizadas.

Naturalmente, podemos reducir el concepto de sociedad civil al de mercado. Pero tampoco en este caso es evidente que el mercado, en el sentido braudeliano, como un lugar de intercambios transparentes y razonables beneficios, se haya ampliado. Es cierto que con la liberalización económica, las políticas de privatización y la transición a la economía de mercado de muchos países periféricos y de los antiguos países socialistas, el número de individuos — personas, empresas, colectivos- participantes en el juego económico se ha incrementado. Pero pudiera ser que compitieran por una cuota de participación en el mercado decreciente en relación con los incrementos del mercado global, en el que impera, hoy como ayer, una combinación de tendencias a la concentración y al monopolio en los sectores punta con un ensanchamiento de la competencia en los sectores maduros y en declive.

Un mercado libre y realmente abierto es algo inestable y, desde luego, ingobernable y peligroso, incluso para los profetas del mercado. Es algo, por tanto, que se predica — para los demás y los escasamente advertidos - si de ello se puede obtener alguna ventaja, pero en lo que no conviene incurrir -p para uso propio-si se corre el riesgo de que las cañas se troquen lanzas. Hay quien sostiene que esa tendencia es tan inherente a la naturaleza humana como la propensión a traficar, y que existiría una contradicción insalvable entre la lógica de la acumulación incesante y la competencia sin tregua, por una parte, y la psico-lógica panhumana, por otra (Balibar y Wallerstein, 1991:227).

No quisiera abusar de los ejemplos que muestran las limitaciones y obstáculos al libre juego del mercado, inscritos en el mismo movimiento por el que se le incita y convoca. Son demasiado numerosos, y tan evidentes como aquella relación entre sexualidad e histeria que todos conocían, pero que fue «invisible» hasta Freud. Tampoco parece razonable hacer esfuerzos por mostrar que no se desea tanto una limitación de la injerencia del Estado en la actividad económica como una utilización de sus poderes en el mutuo beneficio de los poderosos - económica, política, militar o culturalmente-, ahora que han desaparecido, o que están en proceso de remoción, engorrosos obstáculos a la expresión de sus intereses. 
La libre circulación se aplica, así, irrestrictamente a los capitales, pero en absoluto a la mano de obra, y en mucha menor medida a los bienes y servicios. Desde los años sesenta, por ejemplo, pero mucho más acentuadamente a partir de los ochenta - es decir, en pleno esplendor ideológico del librecambismo-, los países más desarrollados han incrementado sus medidas proteccionistas frente a los países periféricos, a los que hay que sumar desde 1989 el antiguo Segundo Mundo (Tortosa, 1993). Esas medidas proteccionistas, según el Banco Mundial, «han logrado reducir el producto interior bruto de los países del Sur en una cantidad equivalente al doble de las ayudas al desarrollo recibidas; ayudas que en su mayor parte se dirigen a la promoción de las exportaciones, y en gran medida a los sectores más ricos (menos necesitados, pero, eso sí, mejores consumidores)» (citado en Chomsky, 1993).

Esa transferencia de recursos de los países pobres a los ricos ascendió entre 1982 y 1990 a unos 400.000 millones de dólares, el equivalente a unos seis Planes Marshall à rebours. En el mismo período, los países deudores remitieron a sus acreedores del Norte $12.450 \mathrm{mi}$ llones de dólares al mes, de los que 6.500 eran intereses. Pese a que el riesgo para la banca comercial del problema de la deuda ha sido conjurado, por la expeditiva vía de los presupuestos públicos, la deuda aumenta cada año, incrementando de paso el deterioro medioambiental, la economía delictiva y de la droga, la destrucción de empleo y la pérdida de mercados, los conflictos bélicos y la inmigración clandestina (George, 1989). La deuda, sin embargo, rinde también réditos políticos a los países centrales, que priman con su reducción controlada el buen comportamiento medioambiental y el apoyo a sus medidas político-militares por parte de los países sureños.

La socialización de costes de una arriesgada política comercial privada no se limita, pese a todo, al problema de la deuda. El mercado es puesto entre paréntesis cuando se trata de industrias punteras o militares, apegadas al abrevadero estatal y cumpliendo torcidamente la Ley de Say en lo que se ha dado en llamar keynesianismo militar o vergonzante. Por supuesto, también cuando el Estado garantiza los depósitos de bancos en quiebra, mediante la transferencia de la morosidad al sector público; mantiene gigantescos gastos militares, pese a sus evidentes efectos depresivos; o sostiene las pensiones o los servicios médicos de las categorías sociales superiores.

Como ha señalado ácidamente Galbraith, el papel del Estado en la cobertura del bienestar se mide con dos varas. Cuando se trata de los desfavorecidos, la cultura económica dominante considera incompatibles las ayudas gubernamentales y la continuidad de la predisposición al trabajo y al esfuerzo. Por el contrario, la «mayoría satisfecha» no sólo soporta admirablemente los efectos adversos de los incentivos materiales procedentes del Estado, sino que los requiere bajo múltiples formas (Galbraith, 1992). 
Pero, sin duda, son las rivalidades en el «core» del sistema mundial la mejor prueba de la relativización de los principios del librecambismo, así como de la eventual predisposición a utilizar la fuerza político-militar como un argumento más frente a los competidores ventajosos (y/o ventajistas) en el mercado. Es, al parecer, lo que pretende Estados Unidos en las actuales negociaciones del GATT (Toinet, 1993; Cassen, 1993).

La economía estadounidense no es, sin embargo, la economía de las corporaciones multinacionales y las instituciones financieras estadounidenses, del mismo modo y en el mismo sentido que las economías europea o japonesa no son reducibles a la cuenta de resultados de sus multinacionales. Es por eso que pueden coincidir una expansión hegemónica de las grandes corporaciones, apoyadas por el poder estatal, y un simultáneo declive de las economías (y de las sociedades) nacionales (Petras, 1992).

La crisis de los años 70 y 80 se caracterizó por la quiebra de pequeñas empresas, de instituciones financieras locales y regionales, y la práctica de fusiones y adquisiciones especulativas. La recesión de los noventa afecta incluso a industrias esenciales $y$, hasta hace poco, vitales en los centros mundiales, al tiempo que la recesión industrial propaga la crisis al sector sevicios, altamente dependiente de la industria cuando se trata de servicios cualificados, y al sector inmobiliario que, a través del incremento de la morosidad, amenaza al sistema financiero (Chossudowsky, 1993).

Sin embargo, el comercio mundial es crecientemente un tráfico de mercancías entre sucursales de unas pocas empresas distribuidas por todo el mundo, o entre empresas unidas por subcontrata -integrados horizontalmente-, como resultado de una utilización jerarquizada y planificada de la división internacional del trabajo (Fröbel, Heinrichs y Kreye, 1980).

Planificada quiere decir «visible», es decir, puño de hierro en mano invisible por esa antigua y curiosa división entre la «racionalidad económica» y la «política» o la «social». Planificada quiere decir también ajena a la competencia, resguardada de la competencia, que se predica sólo para los demás. Ahora bien, ¿tiene algún sentido, en este contexto, hablar de tensiones proteccionistas entre países o entre áreas económicas?

Sólo cuando nos referimos a las viejas economías con base nacional y orientadas al mercado interior. Pero más allá de retóricas nacionalistas y de tensiones proteccionistas entre los polos del comercio mundial, en los que serán sectores punta del futuro se producen acuerdos, se cruzan intereses, se verifica una interpenetración que traspasa las fronteras y que persigue eliminar contradicciones, rivalidades y deficiencias de funcionamiento monopolista, convirtiendo en papel mojado las retóricas localistas. Más aún, las categorías de aná- 
lisis tradicional —en particular, los indicadores de competitividad, o los instrumentos de política comercial- son cada vez más ilusorias ante la imparable progresión de los intercambios entre sociedades matrices y filiales repartidas en múltiples países (Decornoy, 1993).

\subsection{Estado y mercado: el ciudadano consumidor}

Hace ya tiempo Daniel Bell sugirió, con el sentido de la anticipación y la concisa elegancia que le caracteriza, que el Estado resultaba ser demasiado grande para las pequeñas cosas, y demasiado pequeño para los grandes problemas. En lo tocante a la producción y a la circulación del capital siempre lo fue. Como ha señalado Wallerstein, «el hecho mismo de ser burgués impide ser fiel a una comunidad cualquiera, hacer ofrendas a otro dios que no sea Mamón» (Balibar y Wallerstein, 1991:356). Y para despejar las dudas sobre el cosmopolitismo histórico de la burguesía, sobre su carácter mundial, recuerda a los «buenos burgueses» de Amsterdam — sin duda nacionalistas y patriotas- que, mientras luchaban por la independencia contra los españoles en el siglo XVIII, les vendían armas. Tenemos demasiados Irakgates contemporáneos como para singularizar este hecho.

La cuestión de las identidades —nacionales, clasistas, sexuales, raciales, etarias, etc.- es, pues, sobre todo, un asunto que concierne a la gente pequeña en mayor medida que a los «cuadros» forjados en el universalismo. El problema estriba en cómo definimos a esa gente menuda, al conjunto de la sociedad salvo las «élites» (Tortosa, 1992b:490 y ss.). Podemos definirla en tanto que «consumidora», no sólo de bienes de consumo material sino simbólicos, bien sean mensajes políticocomerciales, expedición de credenciales de liderazgo, cultura codificada o «decisiones» sobre las que no puede ejercer la «voz» ni, en función de una recalcitrante homogeneidad, tampoco la «salida».

Pero podemos también definirla en relación con los problemas de la «ciudadanía» y de la democracia, una democracia que, al parecer, debe desistir en su impulso cuando afronta determinados problemas que afectan directamente a la vida inmediata de los individuos. Problemas demasiado complejos, y que deben ser abandonados al criterio de misteriosas sectas que, sólo ellas, conocen las reglas del juego, aunque sea un juego tan natural y acorde con la naturaleza humana como es el juego del mercado.

\section{CONCLUSION}

Es probable, como afirma Dahrendorf, que en los ochenta el giro hacia el neoliberalismo y las políticas de oferta se debiera al hecho 
de que el Estado del bienestar oprimía a muchos con su peso: «a fin de cuentas muchas personas estaban recuperando del Estado lo que habían pagado a la Hacienda Pública a través de sus impuestos descontando el coste de la burocracia estatal $\longrightarrow$ (Dahrendorf, 1993). Se trataba, pues, de recobrar iniciativa y de reaprender un sentido del riesgo adormecido por la omnipresencia estatal: es decir, la vigorosa apuesta thatcheriana (Cairncross, 1991).

La pregunta decisiva, sin embargo, es en favor de quién. El revitalizado liberalismo afirma que, por supuesto, en favor del individuo, un individuo cultivador de las viejas virtudes -familia, duro trabajo y fe-, y presto a obtener las recompensas a su esfuerzo sin aceptar que las normativas estatales distorsionan la jerarquía de los méritos.

Hay muchos modelos de héroe individual en la mitología del liberalismo útiles para fortalecer esta visión. Tenemos, por ejemplo, el modelo Bill Gates y los jóvenes sabios de la informática batiendo a los «gigantes azules». Tenemos el modelo Arriortúa, y su ascenso imparable en la jerarquía de las multinacionales a través de los PICOS. Tenemos, en fin, el ejemplo de la joven tendera metodista, casada con millonario, jefa de gobierno, e ilustre polemista en la Cámara de los Lores.

Podríamos incluso referirnos a nuestros recientes héroes nacionales, hijos exclusivos de su inteligencia, voluntad y esfuerzo. Son ejemplos elocuentes, sin duda, pero que contrastan con la actual desolación de los brokers de los ochenta y el creciente desempleo e inseguridad que afectan a las rampantes «nuevas clases medias», al tiempo que disminuyen las oportunidades de las «viejas», por primera vez en tantas décadas. Malos tiempos para ejemplos vengativos, cuando la movilidad social es descendente más que ascendente, en todo caso horizontal más que vertical, y con regresión de los salarios reales y del nivel y de la calidad de vida con respecto a los progenitores. Sobre todo, en aquellos países en los que la mitología liberal ha brillado, con singular fuerza (Albert, 1992; Heilbroner, 1992; Petras, 1992; Reich, 1992; Thurow, 1992). Conforme a sus propias premisas, la economía del «goteo» no ha percolado la riqueza porque, pese a las curvilíneas promesas lafferianas, no hubo un impulso de crecimiento suficiente ni en ahorro ni en inversión ni, consecuentemente, en producción (Bowles, Gordon, Weisskopf, 1992).

El problema, además, se acentúa cuando a la polarización salarial y ocupacional (Castells, 1991b; Tortosa, 1991), y a la fragmentación social (Mollenkopf, 1992), se añade la necesidad de adquirir en el mercado bienes tales como la sanidad y la educación, cuya libertad de elección es demasiado onerosa, o imposible por debajo de poco usuales rentas. En un mundo que se transforma tan vivaz y rápidamente, las tareas del héroe son sólo encomendables a los héroes, mientras que el conjunto de los individuos no heroicos tiene crecientes dificultades para sobrevivir. 
Tal vez por eso en los últimos años se han reabierto las polémicas en torno a las «identidades» $\mathrm{y}$, de nuevo, el nacionalismo, el sexismo o el racismo -y sus antagonistas ideológicos, el cosmopolitismo, el feminismo, el antisegregacionismo - han cobrado actualidad como motivos en el discurso político y social, algo que probablemente no ocurría desde la frontera de los años setenta.

La segunda respuesta a la deserción del estatalismo pasa, pues, por las diversas entidades que nos constituyen ambiguamente - no como una mezcla que las diluye en un compuesto diferente y único, sino como una mixtura que preserva alguna característica de todas ellas-, que celebramos en los ritos domésticos y en los ritmos privados, y a las que guardamos una difícil y aterida lealtad.

Ahora bien, hay dos formas de afrontar el problema de esas identidades múltiples. La primera es excluyente, propone la «selección natural» de los más aptos independientemente de su origen, y dispone el atizamiento de las diferencias y contradicciones entre los colectivos excluidos. En esta apuesta, al mismo tiempo en favor de la «naturaleza humana» y del «mercado», no es necesario imaginar las combinaciones agónicas de esas identidades azuzadas. Han sido descritas con el austero vigor de un etólogo por Mollenkopf, para el caso de Nueva York, de un modo que recuerda enteramente los informes sobre las luchas «tribales» — como diría el complejo militar-informativo- en el Africa subsahariana (Mollenkopf, 1992).

Tenemos, así, la «lucha por la vida» que enfrenta, según la variable geometría de los intereses de los «amos del universo», a inmigrantes recientes frente a antiguos, a autóctonos frente a alóctonos, a negros frente a asiáticos, a hispanos frente a negros, a pobres honrosos frente a pobres indignos, a mujeres y jóvenes frente a hombres maduros, a trabajadores estables frente a inestables, a autónomos frente a heterónomos, a productores para el mercado frente a burócratas, a los explícitos frente a los sumergidos... A todos, en fin, frente a todos en un estado de naturaleza en el que los individuos viven el presente y se preocupan sólo de su propio bienestar. Como retrodijo Hobbes, en memorable expresión, sus vidas son, así, «solitarias, pobres, desagradables, brutales y breves», aunque conformes a un hipotético destino, a un fatum natural.

La segunda forma de resolver el dilema de las identidades es incluyente, igualitaria en sus objetivos y antijerárquica en la reivindicación de derechos, de títulos de acceso, en la jerga de Darhendorf, tanto a los bienes y servicios esenciales para un digno mantenimiento de la vida, como a la plena ciudadana.

Se basa, por tanto, en otro tipo de «naturalismo», en la reivindicación de cobertura de las «necesidades básicas» —seguridad, libertad, bienestar e identidad, en el escueto balance de Galtung - frente a todo dogma ideológico que no permita su satisfacción, que las conculque o que justifique la imposibilidad de su cumplimiento. 
Dichas «necesidades», además, son universales, es decir, pueden aplicarse a cualquier política o situación en cualquier lugar del planeta, aunque los «satisfactores» puedan variar, y deben contemplarse en su totalidad compleja, sin privilegiar a una en detrimento de las otras (Tortosa, 1992a:80-81). Por último, probablemente dichos requisitos demandan nuevas medidas del Progreso, más acordes con sus posibilidades de existencia para el conjunto de la humanidad, con la continuidad de la vida y con el mantenimiento de los equilibrios medioambientales (Wallerstein, 1988:87 y ss.; Daly, 1991).

Al final de la historia, y tal vez poco antes del fin del hombre como especie, éstas son las verdaderas ideologías en liza, aunque, como se ve, pueden adoptar muchos nombres. Debemos ahora sopesar hasta qué punto la «refolución» del Estado del bienestar (esa síntesis de reforma y revolución, en afortunada expresión de T. GartonAsh), la continuidad de la ciudadanía democrática y su expansión al conjunto de la economía-mundo, son compatibles con la lógica de la acumulación incesante y de la mercantilización generalizada.

En un sentido fuerte, el Estado del bienestar implica la conjunción y el desarrollo de cuatro políticas básicas. Primero, políticas de pleno empleo o tendentes a conseguir un alto nivel de ocupación. Segundo, políticas de seguridad, que procuren abrigo al ciudadano frente a contingencias tales como la enfermedad, los accidentes, la vejez o la pérdida de empleo. Tercero, educación pública asegurada, junto a la garantía de un cierto principio de igualdad de oportunidades. Cuarto, políticas de redistribución de la renta y la riqueza, no sólo en evitación del desorden y la anomia, sino como principio rector en favor de una cierta igualdad.

Algún día el período histórico comprendido entre 1950 y 1968 1973 será estudiado como una «anomalía» en el desarrollo del capitalismo histórico, sólo explicable por el «gran miedo» al largo período de crisis que abarcó desde 1914 a 1945 . Pero el miedo se olvida, el porvenir dura demasiado y pudiera no llegar, y la acumulación tiene sus condiciones. Con toda evidencia, el pleno empleo no sólo no es ya un prerrequisito del Estado del bienestar, sino que desata reivindicaciones incompatibles con la continuidad del sistema y la preservación de equilibrios económicos básicos. Incluso si se produjera una recuperación económica sostenida en los próximos años, un retorno a una Fase A del ciclo Kondratieff, enormes incrementos de productividad serían posibles sin recuperaciones significativas de empleo, salvo si se produjera un incremento equivalente de la demanda y si la industrialización se propagara por todo el mundo.

Ahora bien, esta perspectiva no sólo es especulativa y extrapola la experiencia histórica deducible de la Primera Revolución Industrial, sino que choca con límites medioambientales definidos y minusvalora los costes de las «adaptaciones destructivas» del capitalismo: le mort saisit le vif. 
Aunque la discusión de esta Tesis ocuparía, en sí misma el espacio de un grueso libro (VV.AA., 1992; VV.AA., 1993), la atención al presente y al futuro inmediato, y no a un indeterminado y condicional futuro, indica que el paro es un problema estructural, independiente de la continuidad del crecimiento, y que tasas de desempleo bajas o muy bajas sólo son posibles en aquellas economías altamente competitivas - por definición, sólo unas pocas--, en razón de su tecnología o de la repetición histórica de las condiciones laborales de la Primera Revolución Industrial.

Ahora bien, si el desempleo - en su sentido actual, aunque podemos acordar que la consideración de la actividad, la ocupación y el paro están en proceso de rápido maquillaje estadístico y conceptual- es un dato estructural, no es difícil predecir la quiebra financiera del Estado, salvo que se desresponsabilice de la procura de seguridad, un proceso cuyos signos son cada día más activos. La única forma de asegurar la continuidad de las políticas sociales y de una demanda creciente de la educación sería, paradójicamente, un impuesto que gravara la productividad de las empresas y de los happy few estables, y mantuviera en un ocio subvencionado a una porción creciente de población excedente. Es decir, justamente lo contrario de lo proclamado por la ideología neoliberal, a la que también pueden afectar, al parecer, los «efectos perversos».

Hay, evidentemente, otras alternativas, otros «escenarios» como se dice galicismo mediante, pero no es evidente que respondiesen a la lógica del mercado, que fueran funcionales a la continuidad del sistema. La era del liberalismo, el liberalismo como era, incluso en sus variantes pretendidamente adversas, puede definirse como una promesa de integración paulatina, a través de un cambio racional y competente: un principio esperanza, diferido pero terreno.

Se puede discutir si esa esperanza ha sido defraudada para la mayor parte de la humanidad, como anuncian los apocalípticos (Balibar y Wallerstein, 1991:195-211), o si, como aducen los parusíacos, está a punto de cumplirse en un continente, Asia, que concentra buena parte de la población mundial y presenta tasas de crecimiento inauditas (Berger, 1989; Castells, 1991a). A estas alturas, sin embargo, deberíamos ser más cautos en la lectura de cifras macroeconómicas y de indicadores de salud que descuentan la mortalidad antes del primer año. Sabemos con certeza que la «economía» puede ir bien y, sin embargo, demasiada gente sentirse fatal, como sabemos del retorno de enfermedades que parecían conjuradas, coincidiendo con profundos avances en medicina y biología genética. Otros muchos afirman que en el futuro todos seremos un poquito más pobres, y que esta pobreza relativa será sentida como insoportable por los satisfechos occidentales, cuando es el conjunto de la humanidad la que se enfrenta a su supervivencia, poniendo a prueba los antagónicos, pero complementarios, instintos de lucha y de cooperación (Kolakowski, 1993). 
Todas las instituciones forjadas al calor de esa promesa de crecimiento indefinido y de un futuro necesariamente mejor que el pasado están en crisis, incluyendo una democracia que ha abolido el tiempo a través de la «telepresencia», y el espacio en los flujos veloces de «Redópolis» (Virilio, 1992; Bressand y Distler, 1986). Sin tiempo ni espacio no hay lugar para la discusión, la reflexión, la decisión compartida, el tiempo perdido, que es la esencia del diálogo democrático. Sólo hay lugar para el «integrismo técnico» y una racionalidad económica o tecnocrática, al abrigo de todo cuestionamiento, y que es sólo la otra cara de una creciente irracionalidad social, ésa que se expresa en la xenofobia, los milenerismos y las sectas, y el fanatismo irracional que florece por doquier. La sociedad no existe, como no existe el individuo thatcheriano que decretó la abolición de aquélla. No son nada, independientes de otros subsistemas analíticos - población, economía, política, cultura-, que «irracionalmente» se distinguen en el flujo trabado de lo real, y apenas un eslabón en esa «cadena del ser» de la que hablaban los filósofos antiguos y que abarca desde las células a las estrellas, y aún lo más pequeño y lo más grande.

Alicante, junio 1993

\section{BIBLIOGRAFIA}

Albert, M.: Capitalismo contra capitalismo. Paidós, Barcelona, 1992.

Balibar, E. y Wallerstein, I.: Raza, Nación, Clase. IEPALA, Madrid, 1991.

Bell, D.: Las contradicciones culturales del capitalismo. Alianza, Madrid, 1977.

Berger, P. L.: La revolución capitalista. Península, Barcelona, 1989.

Berman, M.: Todo lo sólido se desvanece en el aire. La experiencia de la modernidad. Siglo XXI, Madrid, 1988.

Birnbaum, N.: «¿El final de la socidad?». En: Miseria de la sociología. Bottomore, T. Tecnos, Madrid, 1982.

Bowles, S.; Gordon, D. M. y Weisskopf, T. E.: Tras la economía del despilfarro. Alianza, Madrid, 1990.

Braudel, F.: Las historias y las ciencias sociales. Alianza, Madrid, 1968.

-: La dinámica del capitalismo. Alianza, Madrid, 1985.

Bressand, A. y Distler, C.: El mundo del mañana, Redópolis. Planeta, 1986.

Bustelo, P.: Economía política de los nuevos países industriales asiáticos. Siglo XXI, Madrid, 1990.

Capra, F.: El punto crucial. Integral, Barcelona, 1985.

Cairncross, F.: «Reino Unido: Rigor sin eficacia». Debats, núms. 35-36, Valencia, 1991.

Cassen, B.: «Vivir sin el GATT». Cuatro Semanas y Le Monde Diplomatique, núm. 5, págs. 12-13, Barcelona, 1993.

Castells, M.: «Ocho modelos de desarrollo tecnológico». Nuevo siglo, núm. 1, págs. 4-14, Madrid, 1987.

-: «La economía informacional, la nueva división internacional del traba- 
jo y el proyecto socialista». El socialismo del Futuro, núm. 4, Fundación Sistema, Madrid, 1991a.

—: «El auge de la ciudad dual: Teoría social y tendencias sociales». Alfoz, núm. 80, Madrid, $1991 b$.

Comte, A.: Discours sur L'esprit positif, UGE, París, 1967.

Chomsky, N.: «Los amos del universo». El País, (28-4), pág. 13, Madrid, 1993.

Chossudowsky, M.: «Los corrosivos efectos de la recesión mundial». Cuatro Semanas y Le Monde Diplomatique, núm. 4, págs. 12-14, Barcelona, 1993.

Dahrendorf, R.: El conflicto social moderno. Mondadori, Madrid, 1990.

-: Reflexiones sobre la revolución en Europa. EMECE, Barcelona, 1991.

-:«Ciudadanía». El País (29-3), pág. 17, Madrid, 1993.

Daly, H. E.: «Criterios operativos para el desarrollo sostenible». Debats, núms. 35-36, Valencia, 1991.

De Miguel, A.: La sociedad española 1992-1993. Alianza, Madrid, 1992.

De Soto, Hernando: El otro sendero. La Oveja Negra, Bogotá, 1986.

Decornoy, J.: «Interdependencia y multipolaridad, caos». Cuatro Semanas y Le Monde Diplomatique, núm. 4, págs. 17-19, Barcelona, 1993.

Foucault, M.: «La gubernamentalidad». En Espacios de poder. Foucault, M. et al. Ediciones de la Piqueta, Madrid, 1981.

Friedman M. y R.: Libertad de elegir. Orbis, Barcelona, 1983.

Fröbel, F.; Heinrichs, J. y Kreye, O.: La nueva división internacional del trabajo. Siglo XXI, Madrid, 1980.

Galbraith, J.: El nuevo estado industrial. Ariel, Barcelona, 1967.

-: La cultura de la satisfacción. Ariel, Barcelona, 1992.

García Cotarelo, R.: Del Estado del bienestar al Estado del malestar. Centro de Estudios Constitucionales, Madrid, 1986.

-: «Origen del Estado de bienestar. Sistema, núms. 80-81, Madrid, 1987.

George, S.: La trampa de la deuda. IEPALA, Madrid, 1989.

Gouldner, A.: Los dos marxismos. Alianza, Madrid, 1983.

Habermas, J.: Problemas de legitimación en el capitalismo tardío. Amorrortu, Buenos Aires, 1973.

Harris, M.: El desarrollo de la teoría antropológica. Siglo XXI, Madrid, 1978.

Hirschman, A. O.: Retóricas de la intransigencia. FCE, México, 1991.

Jhonson, CH.: MITI and the japanese miracle. Stanford University Press, Stanford, 1982.

Jiménez Herrero, L. M.: Medio ambiente y desarrollo alternativo. IEPALA, Madrid, 1989.

-: «Crisis ambiental y desarrollo sostenible». Debats, núms. 35-36, Valencia, 1991.

Jiménez Losantos, F.: «Cultura política». En La sociedad española 19921993. De Miguel, A. Alianza, Madrid, 1992.

Mann, M.: Las fuentes del poder social. Alianza, Madrid, 1991.

Marshall, T. H.: Class citizenship and social development. University Chicago Press, Chicago, 1963.

Mollenkopf, J. H.: «Mundialización económica y fragmentación social en Nueva York». Alfoz, núm. 90, Madrid, 1992. 
Muñoz Bustillo, R.: Crisis y futuro del Estado del bienestar. Alianza, Madrid, 1989.

Oltra, B.: Naturaleza y sociedad. Para una ciencia abierta. Universidad de Alicante, Alicante, 1984.

- : «Para una teoría sociológica de la ciencia». En Escritos de teoría sociológica en homenaje a Luis Rodríguez Züñiga. CIS, Madrid, 1993.

Pahl, R. H.: Divisiones del trabajo. Ministerio de Trabajo y Seguridad Social, Madrid, 1991.

Parsons, T.: La estructura de la acción social. 2 vols., Guadarrama, Madrid, 1968.

Petras, J.: «Expansión exterior y deterioro interno, la dialéctica del poder mundial de los Estados Unidos». Mientras Tanto, núm. 49, Barcelona, 1992.

Polanyi, K.: La gran transformación. Crítica del liberalismo económico. Ediciones de la Piqueta, Madrid, 1989.

Reich, R.: «El gran reto de la economía», Temas de nuestra época, El País (12-11), págs. 4-5, Madrid, 1992.

Ritter, G. A.: El estado social, su origen y desarrollo en una comparación internacional. Ministerio de Trabajo y Seguridad Social, Madrid, 1991.

Rodríguez Cabrero, G.: «Estado de bienestar y política social: concepciones teóricas. Boletín de Estudios y Documentación del INSERSO, núm. 13, Madrid, 1982.

-: «Fundamentos teóricos de la política social». En Política social y Estado del bienestar. Moreno, L. y Pêrez Yruela, M. (comps.) Ministerio de Asuntos Sociales, Madrid, 1992.

Sanchís, E. y Miñana, J.: La otra economía. Trabajo negro y sector informal. Alfons el Magnánim, Valencia, 1988.

Sotelo, I.: «Estado y Sociedad del bienestar». El País (31-1), pág. 12, Madrid, 1993.

Thurow, L.: La guerra del siglo XXI. Javier Vergara editor, Buenos Aires, 1992.

Toinet, M. F.: «El GATT significa "Estados Unidos antes que nadie"». Cuatro Semanas y Le Monde Diplomatique, núm. 4, págs. 15-16, Barcelona, 1993.

Tortosa, J. M.: La perplejidad de las sociedades occidentales como contexto de la politica social. EUTSA, Alicante, 1991.

—: Sociología del sistema mundial. Tecnos, Madrid, 1992a.

—: Problemas sociales. en de Miguel, A., La sociedad española 1992-93. Alianza, Madrid, 1992b.

-: «Transición al mercado y empobrecimiento: Aplicación al caso de Polonia». Sociología del Trabajo, núm. 17, Madrid, 1993.

VV.AA.: «El futuro del trabajo». El Socialismo del Futuro, núm. 6, Fundación Sistema, Madrid, 1992.

-: «El paro, un cataclismo para las sociedades industriales». Cuatro Semanas y Le Monde Diplomatique, núm. 3, Barcelona, 1993.

Virilio, P.: «Cuando ya no hay tiempo que compartir, no hay democracia posible». Alfoz, núm. 90, Madrid, 1992.

Wallerstein, I.: El capitalismo histórico. Siglo XXI, Madrid, 1988.

-: «Análisis de los sistemas mundiales». En La teoría social hoy. Gidens, A. y Turner, J. Alianza, Madrid, 1990. 